\title{
Current and Novel Electrical Generator Technology for Wave Energy Converters
}

\author{
M. A. Mueller (1) Member, IEEE, Henk Polinder (2) Member IEEE, Nick Baker (3)
}

(1) Institute for Energy Systems, School of Engineering \& Electronics, University of Edinburgh, Edinburgh, UK, EH9 3JL.

(2) Electrical Power Processing Group, Delft University of Technology, Delft, Netherlands.

(3) Lancaster University Renewable Energy Group, Engineering Dept., University of Lancaster, UK.

\begin{abstract}
Wave energy is currently an untapped resource, but has the potential to make a significant contribution to the energy mix. In order to use conventional electrical generators mechanical interfaces are used, such as hydraulic systems and air-turbines. With the electrical generator these interfaces are known as the electrical power take-off and the type used depends upon the wave energy device. A brief description of the different power take offs is provided to show how conventional rotary generators are used in wave devices. Both advantages and disadvantages are highlighted in the paper. Direct drive systems can overcome some of the disadvantages, but there are additional engineering challenges to overcome, in particular physical size and mass. Current and more novel direct machine topologies are discussed in the context of these challenges.
\end{abstract}

Index Terms-Wave energy, Linear generators, Permanent magnet machines, Direct Drive.

\section{INTRODUCTION}

$\mathrm{N}$ ational governments throughout the world are committed to generating electricity from renewable energy sources, principally wind, solar and marine renewables, which includes both wave and tidal current. Figure 1 shows an estimate of the world wave resource measured in $\mathrm{kW} / \mathrm{m}$ of wave crest length. European countries with the greatest resource, UK, Portugal and France are leading the way in technology development. In the UK the practical offshore resource is $50 \mathrm{TWh} / \mathrm{y}$, which is $1 / 7^{\text {th }}$ the UK's electricity consumption [2], principally off the West coast of Scotland. There are also significant wave resources on the west coast of North America and off South Africa. The major challenge

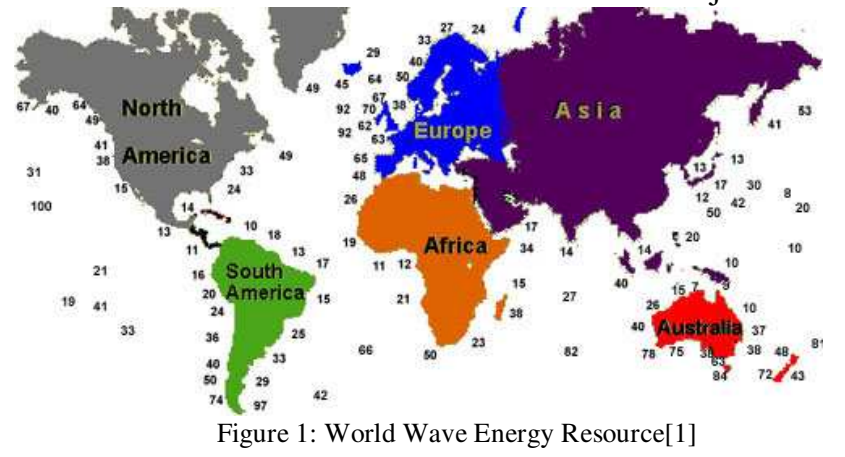

facing wave energy is in capturing it and then transporting this energy to the major load centres. Since the late 1990s European interest in marine renewables has been driven by Kyoto and subsequent government targets to increase the use of renewables in the energy mix. Fundamental and applied R\&D funding has stimulated the growth of a number of technology developers, mainly Small and Medium Enterprises (SMEs) and there have been some full-scale demonstration projects in EU waters. A shoreline device rated at $500 \mathrm{~kW}$ and based on Oscillating Water Column technology (OWC) has been in operation on the island of Islay since 1999 [4]. Ocean Power Delivery demonstrated the Pelamis floating offshore device at the European Marine Energy Centre (EMEC) on Orkney (UK) in 2004, and expect to launch 3 devices off the portuguese coast in 2007 [5]. A Dutch company, Teamwork Technology, developed an offshore sea-bed mounted device known as the Archimedes Waveswing, and a $2 \mathrm{MW}$ rated prototype was demonstrated off the Portugese coast in 2005 [6-9]. A Danish based company, Wavedragon, have demonstrated a $1 / 20^{\text {th }}$ scale floating overtopping device and intend to install a 7MW rated device off the coast of Wales [10]. Each of the wave projects listed are very different, and there are numerous other devices at the development stage, all very different in concept. These projects will be referred to later in the paper to highlight the different ways in which the captured wave energy is converted to electrical power.

It is clear that the technology being developed in wave energy converters is very diverse. Hence choice of the electrical generator is important to ensure optimum performance.

\section{OPERATIONAL RANGE OF MARINE DEVICES}

The marine resource is highly variable. Figure 2 shows annual percentage probability of a particular sea state for wave energy measured at a particular site. At this site the device will experience $20 \mathrm{~kW} / \mathrm{m}$ or less for more than $60 \%$ of the time, but the site can also experience in excess of $100 \mathrm{~kW} / \mathrm{m}$. All components in the device have to be able to survive all sea states. Sizing the power take-off is not easy, and it is likely that the device will be oversized. For example the AWS is rated at $2 \mathrm{MW}$, but the average power rating is $400 \mathrm{~kW}$. Since a device 
will spend most of its operating time at part load, high conversion efficiency at part load is necessary.

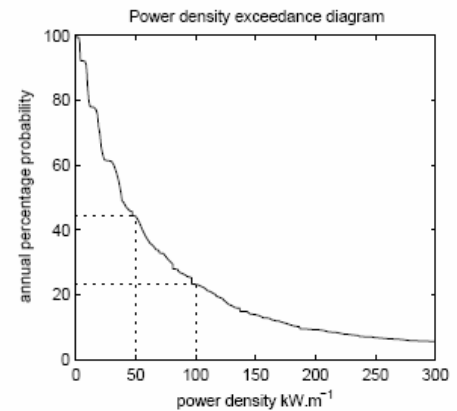

Figure 2: Power Density Exceedance Diagram [11].

Figure 3. illustrates the random nature if the power generated in a wave plant.

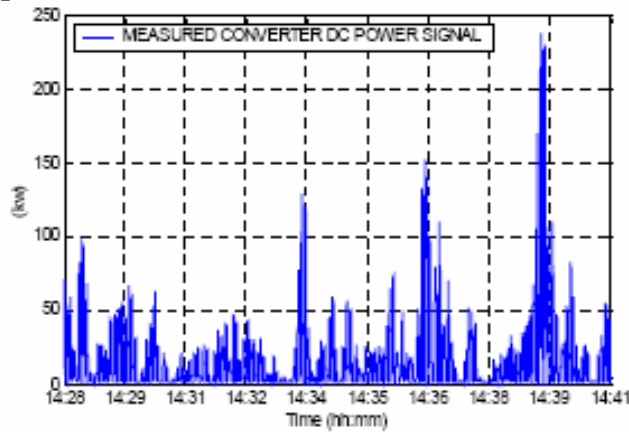

Figure 3: Measured power at the DC link from the AWS device installed off Portugal, 2004[8].

\section{ELECTRICAL POWER TAKE OFF (PTO)}

The power take off system converts the captured mechanical energy into electrical energy. In both wave and tidal systems a mechanical interface can be employed to convert the slow rotational speed or reciprocating motion into high speed rotational motion for connection to a conventional rotary electrical generator. Direct drive is also an option, but is not typical in currently developed marine devices. The energy conversion mechanisms within a wave energy converter can be divided into 3 areas: device, PTO and electrical generation system (including generator and power converter), all of which have losses associated with them.

Table 1 summarises the PTO and generator options for the most advanced wave devices.

TABLE 1

Power take-offs and generators

\begin{tabular}{|l|l|l|l|}
\hline Power take-offs and generators \\
\hline Levice & PTO & Generator & Speed \\
\hline PELAMIS & $\begin{array}{l}\text { OWC \& Wells } \\
\text { Turbine }\end{array}$ & Induction & Variable \\
\hline AWS & Dydraulics & Induction & Fixed \\
\hline WAVEDRAGON & Water-turbine & Rotary PM & Variable \\
\hline PICO & $\begin{array}{l}\text { OWC \& Variable } \\
\text { Pitch Turbine }\end{array}$ & DFIG & Variable \\
\hline ENERGETECH & $\begin{array}{l}\text { OWC \& Variable } \\
\text { Pitch Turbine }\end{array}$ & Induction & Variable \\
\hline
\end{tabular}

\section{B. Hydraulic Systems.}

The reciprocating motion in a wave device can be used to pump a fluid. Figure 5 shows a basic schematic of a floating device driving a hydraulic system based upon oil using axial displacement rams pumping fluid around the system to drive a hydraulic motor, which is then coupled to a conventional offthe-shelf induction machine. Accumulators provide energy storage to compensate for the variations in power shown in Figure 3. 


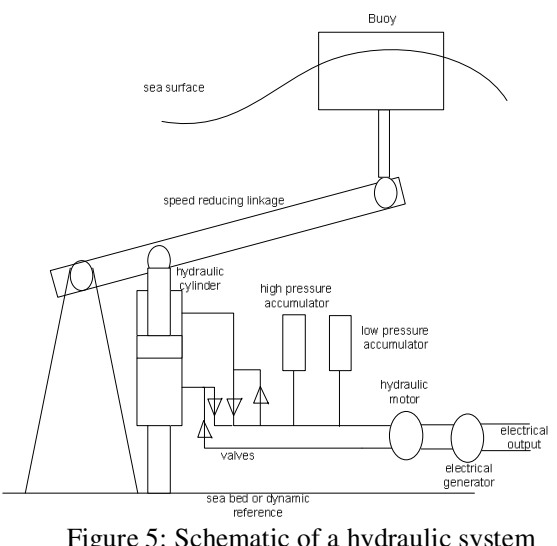

Such a system is deployed within the Pelamis, but fully enclosed within the device rather external to the device as represented here. Alternatively as shown in reference [14] a device can be used to pump water and drive a water turbine.

Hydraulic systems utilizing high pressure oil tend to be proposed for floating devices to take advantage of their high energy density to accommodate weight and size restrictions. However, axial displacement hydraulic systems require low speeds of operation because of the limitation of the seals. If there is any leakage of sea-water into the system through the seals the hydraulic fluid would become contaminated leading to reduced performance. Axial Displacement Hydraulic systems exhibit poor part load efficiency, as shown by Payne et al [11] and reproduced in Figure 6.

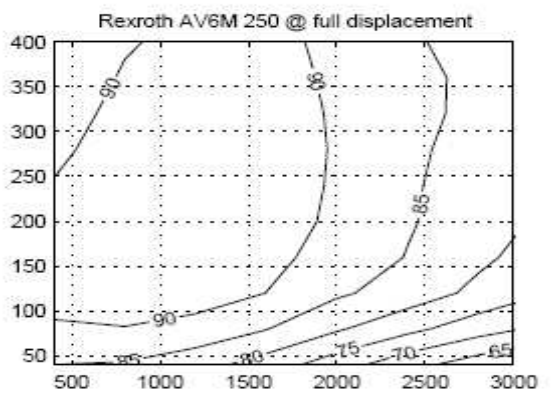

Figure 6(a): Full load displacement efficiency curves

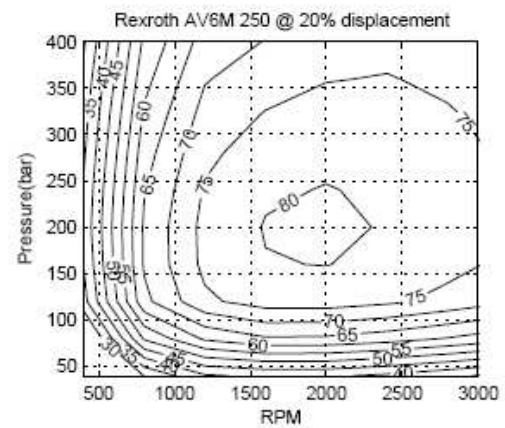

Figure 6(b): Part load displacement efficiency curves

At full displacement the efficiency varies between 90 and $60 \%$ but at part displacement the efficiency map is very peaky, with a maximum of $80 \%$, but falling rapidly to away from the optimum operating point.

\section{Water Turbines}

Water turbines can be used in hydraulic pumping systems where the fluid is water [14], but recently they have been proposed for so-called overtopping devices, which is essentially a low-head hydro system. The principle of operation of such devices is shown in Figure 7. Waves crash over the device into a floating reservoir, which in turn feeds a water turbine coupled to conventional rotary generators.

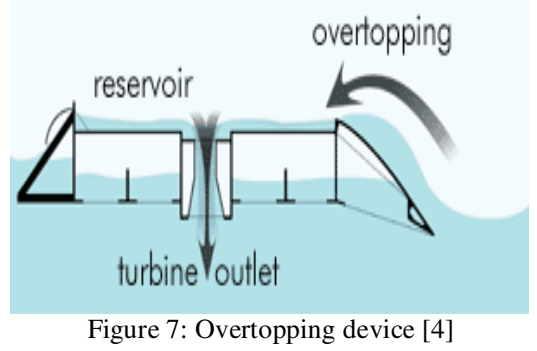

Knapp et al show that the efficiency of a Kaplan water turbine is in excess of $90 \%$. It is not so easy to estimate the efficiency or effectiveness of the overtopping aspect of the actual device. This device does have the advantage of energy storage, few moving parts, and uses conventional low head hydro technology. The Wavedragon [4] is one example of such a system, but there are also variations on this theme such as the Waveplane [15]. High pole number synchronous PM generators running at high frequency are used to reduce size and weight.

\section{Direct Drive}

In a direct drive system there is no mechanical interface coupling the device to the electrical generator. Hence it has the potential to provide a simpler system requiring fewer moving parts, lower maintenance requirements and higher efficiency. Now the velocity of the generator is equal to that of the primemover, being of the order of $0.5-2 \mathrm{~m} / \mathrm{s}$. In order to generate any amount of power the machine will therefore have to react large forces. Machines typically have an airgap shear stress in the region of $20-40 \mathrm{kN} / \mathrm{m}^{2}$. Hence if the machine rating is $2 \mathrm{MW}$ at $2 \mathrm{~m} / \mathrm{s}$, the force is equal to $1 \mathrm{MN}$, which will require an airgap surface area of $25 \mathrm{~m}^{2}$ at best. Direct drive machines are physically very large and heavy. The concept of direct drive has been demonstrated within the Archimedes Wave Swing device [7-9]. Figure 9 shows the principle of operation of the device and a photo of the device pre-installation. The device is sea-bed mounted. It consists of an air-filled chamber with a floater that moves down with the crest of a wave and up with the trough of a wave. 


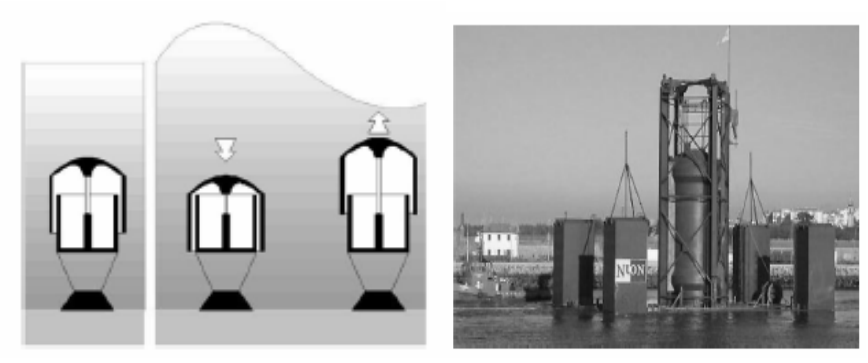

Figure 9: Archimedes Waveswing

The power take-off could be a hydraulic system, but a double sided linear permanent generator has been used in this device. Figure 10 shows the generator being installed and the calculated efficiency of the generator under various wave amplitudes and frequency
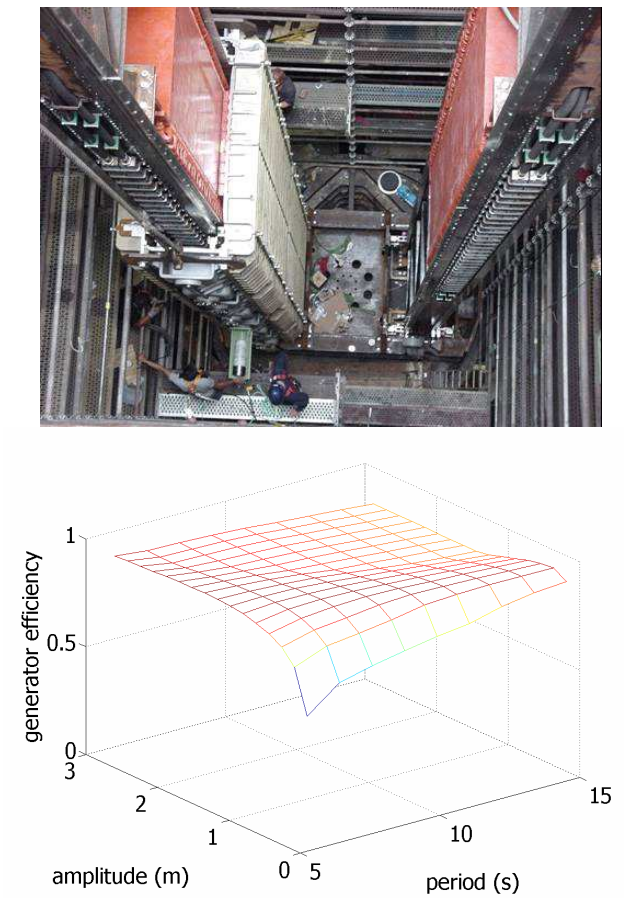

Figure 10: AWS Linear Generator and its efficiency map

The shear scale of the generator can be seen by noting the two engineers at the base of the generator. From the efficiency graph the linear generator exhibits high efficiency (> 90\%) over a wide range of wave amplitudes and periods. Typically the wave period in the North Atlantic is $10 \mathrm{~s}$ and wave amplitude of $1-3 \mathrm{~m}$. Hence by eliminating the mechanical interface between the device and the generator the overall system efficiency is expected to be higher in direct drive.

\section{DIRECT DRIVE GENERATORS}

\section{A. Review}

Direct drive is being used by some manufacturers in the wind industry as an alternative to gearbox drive trains because of reliability issues. Likewise in the marine renewable sector direct drive is an attractive option in terms of improved system efficiency, reliability and robustness. The calculated efficiency of the linear generator used in the AWS partly supports this argument, but there is too little practical experience to make any conclusions regarding reliability.

The AWS experience illustrates clearly the issue of size and weight of direct drive linear generators. As shown earlier the airgap surface area is large due to the low velocity of the machine. The mass of a machine can be divided into two parts: active material consisting of magnets, copper and steel laminations and inactive material consisting mainly of steel, which provides structural support to maintain the physical airgap between the moving and stationary parts. McDonald et al [16] have shown that for direct drive rotary machines the inactive part can be greater than $60 \%$ of the total mass. This inactive component is required principally to overcome the Maxwell Stress force, which acts normal to the airgap surface. Typically the airgap flux density in a PM machine for direct drive would be of the order $0.6 \mathrm{~T}$, which translates to a Maxwell stress of $143 \mathrm{kN} / \mathrm{m}^{2}$. Using the airgap surface area calculated in section $5,25 \mathrm{~m}^{2}$, the total normal magnetic attraction force will be of the order of $3.6 \mathrm{MN}$. The structure and bearing system have to be designed with this force in mind. The forces can be made to balance by adopting a double sided topology with equal airgaps on both sides, but due to manufacturing tolerances in very large machines there will be some difference in airgap along the length of the machine. As well as the magnetic forces the machine has to be designed to take into account loadings due to interaction with the marine resource, which include non-reversing loads due to wind, tidal currents and cyclic loading due to wave action. The size of the loading depends upon the resource and the submerged depth.

After having designed a conventional linear PM synchronous machine for the AWS Polinder et al [17] compared a number of different machine topologies: including, the linear induction machine, PM synchronous machine, both iron and air-cored, and the switched reluctance machine. The final results show that the iron-cored PM machine designed and built for the AWS came out on top in terms of cost $/ \mathrm{kW}$. A novel high force density transverse flux machine introduced in the paper also looked very promising. However, the comparison was based entirely on the active components of the machines, and did not take into account the mechanical aspects. It is clear from discussion in previous paragraphs that an integrated design approach needs to be adopted for direct drive marine renewable systems in order to take into account the structural and bearing requirements of a linear generator, as well as the environment, in which it is applied, and any comparison should reflect that.

\section{B High force density topologies}

Variable Reluctance Permanent Magnet (VRPM) machines such as the transverse flux machine (TFM) exhibit shear stresses orders of magnitude greater than a conventional PM machine topology. For example, Weh [18] presented results indicating a shear stress up to $200 \mathrm{kN} / \mathrm{m}^{2}$. Such a machine could reduce the airgap surface area by a factor of 5 for marine applications. Mueller \& Baker [19] have built a linear vernier hybrid PM machine (VHM), which is also a member of the 
VRPM family, but it uses laminations and is more straightforward to construct. Figure 11 shows a photograph of a linear VHM prototype machine built and further details can be found in [19]. In the VHM the magnets are mounted on the stationary part of the machine, and hence the amount of PM material is minimized compared to the TFM. The stator consists of c-cores placed in pairs facing each other, with each pair making up one phase. Coils are wound around c-core limbs. The moving translator is sandwiched between the stationary c-core stator. A shear stress in excess of $100 \mathrm{kN} / \mathrm{m}^{2}$ was measured for a current of 20A [19].

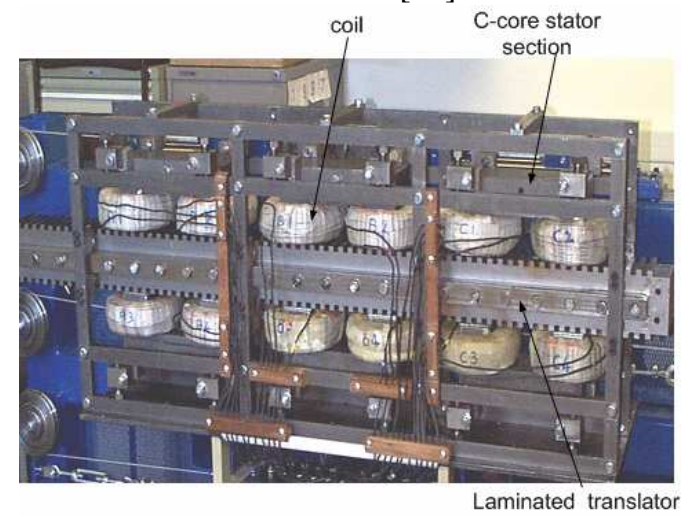

Figure 11: Prototype linear vernier hybrid PM machine

These machines exhibit high inductance $-0.5 \mathrm{H}$ per phase for the machine in Figure 11. A low power factor results, and for the prototype above a value in the region of 0.1 was estimated from measurements. For the TFM power factors as high as 0.5 can be obtained if using buried magnets [20. VRPM machines rely upon having very small airgaps $(<1 \mathrm{~mm})$ because of the small magnet pitch. Maintaining a small airgap in a linear machine $2-3 \mathrm{~m}$ in length or at a similar diameter for a rotary machine will be very difficult due to manufacturing tolerances. If the airgap were to increase significantly without an increase in magnet pitch most of the PM flux would not cross the gap and simply link the neighbouring magnet. If the magnet pitch is increased in line with the airgap, the machine begins to resemble a conventional PM synchronus machine.

A significant support structure is required to overcome the large magnetic attraction forces and also any vibration. Figure 12 shows the calculated airgap closing force for the prototype VHM, which peaks at 2.7 times the useful tangential force. The cyclical variation compounds the structural and bearing requirements.

\section{Low force density topologies}

Significant structural savings can be made if the normal magnetic attraction forces can be reduced or eliminated, which can be achieved by constructing a stator which contains no iron such that the coils are supported in air - a so-called air-cored stator. In reference 23 Polinder includes an air-cored PM machine, in which the air-cored stator is sandwiched between two iron PM translators with PMs of opposing polarity facing each other, so that flux shines through the winding.
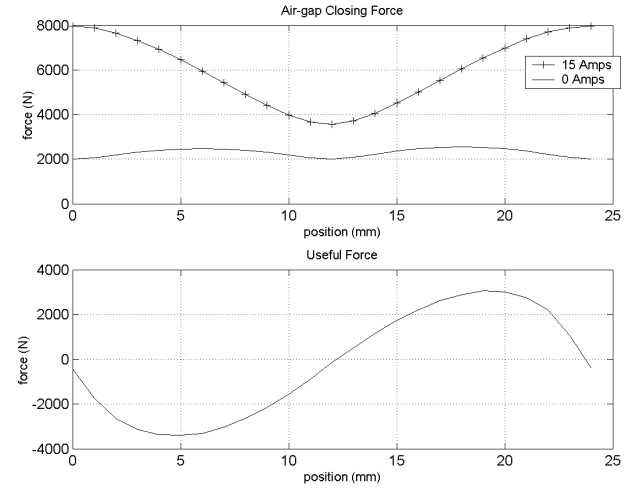

Figure 12: Airgap closing force and useful tangential force [21].

The magnetic force between the stator and translator has been eliminated, but there will still be a significant attraction force between the two PM translators. Complete elimination of the attraction force is obtained using an air-cored PM tubular topology as shown in figure 12. The magnets are axially magnetized and sandwiched between steel pieces on the translator. Toroidal coils are supported in a non-magnetic material around the translator. A prototype machine has been built and tested $[21$.

Mechanically this is a very simple machine, as the Maxwell stress force has been completely removed. A radial Lorentz force does exist, but is of the same order of magnitude as the useful axial force as shown in Figure 13. These results have been generated for a constant current, but it should be noted that it is unlikely that the peak current will coincide with the position of peak radial force.

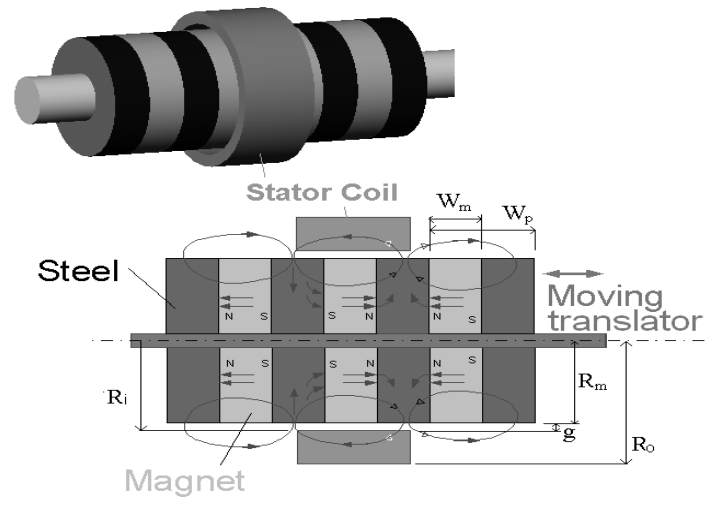

Figure 12: Air-cored PM tubular machine

In the air-cored machine the flux density from a pole face decays rapidly above the translator surface, as shown in the right hand graph in Figure 13. For the prototype an average shear stress of $20 \mathrm{kN} / \mathrm{m}^{2}$ was calculated for a coil current of 10A. Reasonable shear stresses are possible but at the expense of high current, which will contribute to the losses.

\section{DISCUSSION}

Marine renewable energy converters do not lend themselves to the direct application of conventional off-the-shelf rotary 
generators such as the induction machine. The need to use a mechanical power take off interface so that an induction machine can be used results in additional losses affecting the overall system efficiency. This additional loss can be eliminated by adopting the direct drive solution. However, there are significant mechanical engineering challenges to be overcome in integrating direct drive in marine energy devices. The major issue is size and weight
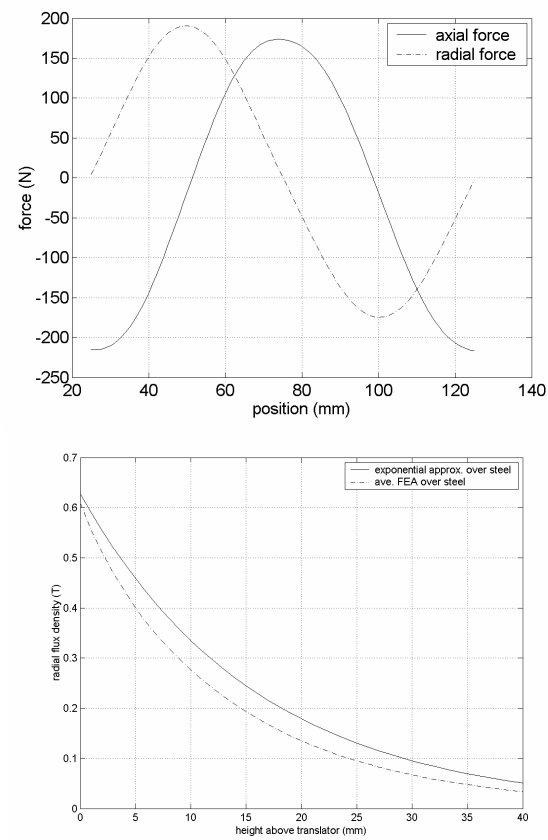

Figure 13: Radial and axial force; decay of radial field with height above the translator surface

Devices where physical space is an issue can therefore not benefit from direct drive - the Pelamis is one example. Recent advancements in radial displacement hydraulic technology exhibit high part load efficiencies as shown in reference 11 and hence could be of benefit to devices like the Pelamis. The shear size and mass of direct drive machines can be tackled using two alternative routes: using high force density machines or at the other extreme low force density machines. Based upon the information given in section IV it is clear there are pros and cons of each. The optimum solution will very much depend upon the actual topology of the marine device, and hence a highly integrated approach is required. Comparisons of machine types need to take into account the structural integration of the generator into the device, which should also include the bearing design. Such an integrated design approach should form the next stage in the development of direct drive solutions. This paper has focused on the generator, but it should be noted that all examples discussed a power converter is required to interface to the grid. The only exception to this is the Pelamis device, in which the induction machine runs at fixed speed.

\section{CONCLUSION}

A brief insight into the methods of electrical power generation in marine renewable energy converters has been presented. The use of mechanical interfaces such as gearboxes, hydraulics or air/water turbines has been driven by the desire to use high speed rotary electrical generators. In some cases this will lead to a reduction in overall system efficiency. Direct drive has the potential to result in a more efficient and reliable system, but there are electrical and mechanical challenges to overcome. Attempts to identify the optimum direct drive generator topology have been made, but from a purely electrical perspective. The optimum solution will very much depend upon the actual topology of the marine device, and hence a highly integrated approach is required.

\section{REFERENCES}

[1] www.oceanpd.com/Resource/Worldresourcemap.html (last accessed January 2007)

[2] ETSU (1985), The Department of Energy's R\&D Programme 19741983,ETSU Report R-26.

[4] Www.wavegen.co.uk (last accessed January 2007)

[5] www.oceanpd.com/ (last accessed January 2007)

[6] www.awsocean.com )last accessed January 2007)

[7] H. Polinder, M.E.C Damen, F. Gardner \& M.G. de Sousa Prado "Archimedes wave swing linear permanent-magnet generator system performance", 6th European Wave and Tidal Energy Conference, Glasgow, Aug. 2005

[8] Prado, M. G. S.; Neumann, F.; Damen, M. E. C.; Gardner, F., “AWS results of pilot plant testing 2004", $6^{\text {th }}$ European Wave and Tidal Energy Conference, Glasgow, Aug. 2005

[9] H Polinder, F Gardner, B Vriesema, "Linear PM Generator for wave energy conversion in the AWS", Proc of the International Conference on Electrical Machines, August 2000, Espoo, Finland, pp 309-313.

[10] www.wavedragon.co.uk (last accessed January 2007)

[11] GS Payne, UBP Stein, M Ehsan, NJ Caldwell \& WHS Rampen, "Potential of Digital Displacement Hydraulics for Wave Energy Conversion", Proceedings of the 6th European Wave \& Tidal Energy Conference, Aug/Sept 2006, Glasgow, UK.

[12] J.W. Weber \& G.P. Thomas, "Optimisation of the Hydrodynamicaerodynamic coupling for an Oscillating Water Column wave energy device", Proceedings of the $4^{\text {th }}$ European Wave Energy Conference, Aalborg, 2000.

[13] T.J.T. Whittaker, T.P. Stewart, S. Raghunathan \& R. Curran, "Implications of operational experiences of the Islay OWC for the design of Wells' turbines", Proceedings of the $2^{\text {nd }}$ European Wave Energy Conference, Lisbon, Portugal, Nov. 1995.

[14] http://finavera.com/wavetech (last accessed January 2007)

[15] Rasmussen \& Skaarup, "Working principles of the WavePlane", Proceedings of the $4^{\text {th }}$ European Wave Energy Conference, Aalborg, 2000

[16] M.A. Mueller, A.S. McDonald \& D.E. Macpherson "Structural Analysis of Low Speed Axial Flux Permanent Magnet Machines", IEE Proceedings on Electric Power Applications, Vol. 152, No. 6, pp14171426, November 2005, ISSN 1350-2352

[17] H Polinder, B. Mecrow, A. Jack, P. Dickinson, \& M.A. Mueller, "Linear Generators for Direct Drive Wave Energy Conversion", IEEE. Trans. On Energy Conversion, Vol. 20, No. 2, pp 260-267, June 2005, ISSN 08858969.

[18] Weh H, Hoffman H \& Landrath J, "New Permanent Magnet Excited Synchronous Machine with High Efficiency at Low Speeds.", Proc. Int. Conf. Elec. Machines, Pisa, Italy, Sept. 1988, pp35-40.

[19] M.A Mueller, \& N.J Baker, "Direct Drive Wave Energy Converters", IMech.E Journal of Power and Energy, Vol. 219, No. A3, pp 223-234, May 2005.

[20] M.R Harris., G.H. Pajooman, \& S.M. Abu Sharkh, "The Problem of Power Factor in VRPM (Transverse Flux) Machines.", Proc. IEE Conference on Electrical Machines \& Drives, Cambridge, 1997.

[21] N.J. Baker, "Linear Generators for Direct Drive Marine Renewable Energy Converters", PhD Thesis awarded by University of Durham, 2003 